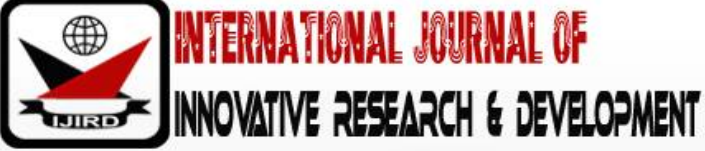

ISSN 2278 - 0211 (Online)

\section{Management of Executive Stress among University Administrators in North-Western Nigeria: Implications for School Administrators}

\author{
Dr. Sani Dantani Manga \\ Associate Professor, Department of Educational Foundations, \\ Faculty of Education and Extension Services, Usmanu Danfodiyo University, Sokoto, Nigeria
}

\begin{abstract}
:
This paper assessed the prevalence, causes and symptoms of stress among University Administrators in Universities in North- Western Nigeria, as well as stress management strategic that could be applied to prevent stress among School Administrators. This study adopted a simple descriptive design. The population of the study comprised of all the Universities in North Western Nigeria made up of State and Federal Universities. One University was deliberately selected from each of the seven states that make up the North- West geo-political zone. The Universities selected included both Federal and State owned. University Administrators included Vice-Chancellors, Deputy Vice Chancellors, Registrars, Librarians, Deans, Directors, Bursars and Heads of Departments, to get a total of 20 participants from each university. The total participants from the seven Universities were 140. The instrument for the study was a self-designed questionnaire titled: Executive Stress Management Questionnaire (ESMQ). The instrument was structured and based on a five-point Likert Scale. It was validated by educational management experts and after pilot-testing it had a reliability index of 0.78 . The cut-off mean for decision was set at 2.50 and above for agreement, while mean of below 2.5 was to determine rejection based on weighted mean. Data was collected with the use of trained research assistants who personally visited selected Universities and administered the questionnaire. The study found that the prevalence of stress among University Administrators in Universities in Northern Nigeria is high as they are affected by various sources of stress on daily basis. Most of them have symptoms of stress but do not agree on stress management strategies. It was therefore recommended that educational management experts should organize regular symposium, and workshops for University Administrators so as to enable them to recognize symptoms of stress and the kind of management strategies they can use to prevent stress.
\end{abstract}

Keywords: Executive stress, university administrators, management, strategies

\section{Introduction}

Every school administrator aspires to perform his duties efficiently and effectively for the realization of organizational goals. In pursuit of their vision, many school administrators tend to overwork and overstretch their capacities beyond normal limits, thereby resulting in stress. Thus, one of the most common forms of stress affecting millions of people is that related to one's career and workplace (Nuget, 2017). Workers generally and the University Administrators in particular are bombarded by various sources of stress on daily basis. The executives in the Universities are constantly exhausted by their cumbersome and tight schedules in the face of intense demands of office placed on them by their subordinates and the general public, which seriously stresses them out, keeps them perpetually anxious and often sleep deprived. Horn by (2013), view stress as a state of mental or emotional strain or tension, resulting from adverse or demanding circumstances. It is an individual's response to a strong stimulus called a stressor. The University being a very complex organization has a lot of complex activities that keeps all staff fully loaded with excess workloads that are not easy to cope with even by the most hardworking staff. The University Administrators in this paper are operationalized to include the Vice-Chancellors, Deputy Vice Chancellors, Deans of Faculties, Directors, and Heads of Departments, Registrars, Bursars and other critical office holders in hot bureaucratic structure of university administration.

Universities all over the world are highest citadels of learning and centers of excellence for knowledge production. Their efficiency and effectiveness are source of concern for all citizens of a country. North-Western Nigeria has a number of Universities that must be run in line with national and global best practices. But the extents to which Universities are properly managed largely depend on the skills, efforts and managerial productivity of the University Administrators. However, due to the complex nature of the University system, University Administrators are under great pressure to provide the desired leadership for the day to day running of the Universities. This high expectation naturally generates stress on the University Administrators. 


\section{Statement of Problem}

Executive stress can be caused by many factors. Nuget (2017) stated that University Administrators are confronted with heavy workload with unrealistic deadline for urgent completion. They have little or no time for breaks due to their busing schedules. Because several tasks completing for attention at the same time, the University Administrators have the tendency to engage in multi-tasking all of which subject them to stress. Keith (2017)observes that lack of time for exercise, sleeplessness and poor diet all cumulatively add up to cause and intensify executive stress. In his view, McDowell (2017) believes that executive stress can be caused by excessive pressure by superiors and subordinates, lack of delegation, and being too hard on oneself. In addition, conflicting personal and office goals, lackof proper communication and a reward system that is not based on job performance equally contribute to executive stress.

Whatever may be the source of stress the symptoms of stress are usually manifested in several ways. Julie (2017) noted that the symptoms of executive stress are inefficiency, declining productivity,' irritability and strained relationships. Penelope (2017) identified memory lapses, physical and mental fatigue, body pains and loss of objectivity as critical symptoms of executive stress. In addition, stress symptoms include feelings of being rushed; overwhelmed and unable to cope, as well as incomplete and abandoned tasks.

In spite of the symptoms and consequences of stress, many University Administrators do nottake serious measures to prevent stress. Goldberg (2017) notes that many University Administrators are unaware of their stressors and are therefore unable to determine their stressors as well as their body response signalsto stress. Madison (2017) states thatmany University Administrators do not engage inregular exercises, relaxation and properdieting as stress prevention strategies. Edberg (2017) notes that executive stress prevention efforts are marred by some University Administrators indulging in smoking, drugs, alcoholism, sleep deprivation and poor time management. Thus, the main thrust of this paper was to examine the causes of executive stress, its major symptoms and preventive strategies that could be applied by University Administrators in Universities in North-Western Nigeria.

\section{Research Questions}

The following research questions were formulated to guide the conduct of this study:

- What is prevalence of stress among University Administrators in Universities in North Western Nigeria?

- What are the causes of executive stress among University Administrators in Universities in North-Western Nigeria?

- What are the symptoms of executive stress prevalent among University Administratorsin North Western Nigeria?

- What are the management strategies to be applied to prevent executives stress among University Administrators in Universities in North Western Nigeria?

\section{Objectives of the Study}

The objectives of this study are as follows:

- To find out the prevalence of stress among University Administrators in Universities in Northern Western Nigeria.

- To find out the causes of executive stress among University Administrators in Universities in Northern Western Nigeria.

- To ascertain the symptoms of executive stress that is prevalent among University Administrators in Universities in North-Western Nigeria.

- To determine the management strategies that can be applied to prevent executive stress among University Administrators in Universities in North-Western Nigeria.

\section{Methodology}

This study adopted a simple descriptive design. The population of the study comprised of all the Universities in North Western Nigeria made up of State and Federal Universities. One University was deliberately selected from each of the seven states that make up the North-West geo-political zone. The Universities selected included both Federal and State owned. University Administrators included ViceChancellors, Deputy, Vice Chancellors, Registrars, Librarian, Deans, Directors, Bursars and Heads of Departments, to get a total of 20 participants from each university. The total participants from the seven Universities were 140. The instrument for the study was a self-designed questionnaire titled: Executive stress Management Questionnaire (ESMQ). The instrument was structured and based on a five-point Likert Scale. It was validated by educational management experts and after pilot-testing it had a reliability index of 0.78 . The cut-off mean for decision was set at 2.50 and above for agreement, while mean of below 2.50 was used to determine rejection based on weighted mean. Data wascollected with the use of trained research assistants who personally visited selected Universities and administered the questionnaire.

\section{Results}

Results of the study were computed using summative rating scale, otherwise called weighted mean and presented in tables 13.

\subsection{Research Questions One}

- RQ 1: What is the extent of prevalence of stress among University Administratorsin North Western Nigeria?

This research question was answered and presented in table 1. 


\begin{tabular}{|c|c|c|c|}
\hline S/ N & Prevalence of Stress & Means & Decisions \\
\hline 1 & Very High & 3.90 & Agree \\
\hline 2 & High & 3.63 & Agree \\
\hline 3 & Moderate & 3.00 & Agree \\
\hline 4 & Low & 2.40 & Disagree \\
\hline 5 & Very low & 2.00 & Disagree \\
\hline 6 & Non-existent & 2.04 & Disagree \\
\hline & Overall & 2.82 & Agree \\
\hline
\end{tabular}

Table 1: Mean Scores of Extent of Prevalence of Stress among

University Administrators Universities in north Western Nigeria

Table 1 shows that the participants among University Administrators in Universities in North Western Nigeria range from moderate, High and Very High as indicated by the mean ratings of 3.903 .63 and 3.00respectively. The overall mean of 2.82 indicate that the prevalence of stress is a reality among University Administrators of Universities in North Western Nigeria.

\subsection{Research Questions Two}

- RQ2: What are the causes of Executive Stress among University Administrators inNorth Western Nigeria? This research question was answered and presented in table 2.

\begin{tabular}{|c|c|c|c|}
\hline S/ N & Causes of Executive Stress & Means & Decisions \\
& & $X$ & \\
\hline 1 & Heavy workload & 4.60 & Agree \\
\hline 2 & Unrealistic deadlines & 4.30 & Agree \\
\hline 3 & Lack of breaks & 4.00 & Agree \\
\hline 4 & Several tasks competing for attention & 4.20 & Agree \\
\hline 5 & Multi-tasking & 4.40 & Agree \\
\hline 6 & Lack of time for exercise & 3.70 & Agree \\
\hline 7 & Sleeplessness & 3.80 & Agree \\
\hline 8 & Poor diet & 2.00 & Disagree \\
\hline 9 & Excessive pressure by superiors & 4.50 & Agree \\
\hline 10 & Lack of delegation & 2.30 & Agree \\
\hline 11 & Being too hard on oneself & 2.80 & Agree \\
\hline 12 & Conflicting personnel and official goals & 2.90 & Agree \\
\hline 13 & Poor communication & 2.13 & Agree \\
\hline & Overall & 3.50 & \\
\hline
\end{tabular}

Table 2: Mean Scores of Causes of Executive Stress among University Administrators in Universities in North Western Nigeria

Table 2 shown that majority of participants do not agree that poor diet, lack of delegation and poor communication are among the causes of stress that affect them as reflected in items 8, 10, and 13 with mean scores of 2.00 , 2.30 and 2.13 respectively. They however, agree with all the remaining items with mean score ranging from 2.90 to 4.60 . In other words, they agreed that heavy workload unrealistic deadlines, lack of breaks, several task competing for attention, multitasking, lack of time for exercise, sleeplessness, excessive pressure by superiors, being too hard on oneself as well as conflicting personal and official goals are among causes of stress. The overall mean of 3.50 shows that as a whole, University Administrators in Universities in North Western Nigeria agree on the various sources of stress identified in table 1.

\subsection{Research Question Three}

- $\quad$ RQ3: What are the symptoms of executive stress among University Administrators in North

Western Nigeria?

This research question was answered and presented in table 3 


\begin{tabular}{|c|c|c|c|}
\hline S/ N & Symptoms of Executive Stress & Means & Decisions \\
& & $\bar{X}$ & \\
\hline 1 & Inefficiency in job performance & 2.90 & Agree \\
\hline 2 & Declining productivity & 3.50 & Agree \\
\hline 3 & Irritability on trivial issues & 3.00 & Agree \\
\hline 4 & Strained interpersonal relationships & 3.70 & Agree \\
\hline 5 & Memory lapses on vital issues & 3.40 & Agree \\
\hline 6 & Physical fatigue & 3.60 & Agree \\
\hline 7 & Mental fatigue & 3.30 & Agree \\
\hline 8 & Bodily pains & 4.00 & Agree \\
\hline 9 & Loss of objectivity in judgment & 4.09 & Agree \\
\hline 10 & Feeling of being rushed and overwhelmed & 4.50 & Agree \\
\hline 11 & Ability to cope with workload & 4.05 & Agree \\
\hline 12 & Uncompleted and abandoned works & 4.03 & Agree \\
\hline & Overall & 3.60 & Agree \\
\hline
\end{tabular}

Table 3: Means Cause of Symptoms of Executive Stress among University Administrators in North Western Nigeria

Table 3 indicates that University Administrators agreed with all the symptoms of executives' stress listed in items 1 to 12 with mean scores ranging from 2.90-4. 50. This overall mean score of 3.60 Simples that University Administrators in Universities in North Western Nigeria agree that they experienced these symptoms of stress listed in table

\subsection{Research Question Four}

- RQ4: What are the management strategies to be applied to prevent executive stress among University Administrators in Universities in North Western Nigeria.

This research question was answered and presented in table 3.

\begin{tabular}{|c|c|c|c|}
\hline S/ N & Management Strategies for Stress Prevention & $\begin{array}{c}\text { Means } \\
\end{array}$ & Decisions \\
\hline 1 & Engaging in regular physical exercises & 1.00 & Disagree \\
\hline 2 & Make time for relaxation and breaks & 3.80 & Agree \\
\hline 3 & Embarking on proper dieting & 1.01 & Disagree \\
\hline 4 & Stop smoking & 2.10 & Disagree \\
\hline 5 & Avoid drugs to boost performance & 2.50 & Agree \\
\hline 6 & Avoid alcoholism to relieve tension & 5.00 & Agree \\
\hline 7 & Have adequate sleep & 2.50 & Agree \\
\hline 8 & Better management of time & 1.04 & Disagree \\
\hline 9 & Avoid multi-tasking & 1.02 & Disagree \\
\hline 10 & Reduce workload by delegation & 2.50 & Agree \\
\hline 11 & Realistic deadlines for task completion & 2.50 & Agree \\
\hline 12 & Avoid being too hard on yourself & 2.50 & Agree \\
\hline 13 & Do not insist on perfectionism & 2.50 & Agree \\
\hline & Overall & 2.80 & Agree \\
\hline
\end{tabular}

Table 4: Mean Scores of Management Strategies for Prevention of Stress among University Administrators In North-Western Nigeria

Table 4 shows that the Chief Executing in Universities do not agree that exercise, dieting, smoking, time management and avoidance of multitasking are effective stress management strategies as reflected in items $1,3,4,8$, and 9, which they rated between 2.04 to 2.20 . They however agreed that taking breaks for relaxation, avoidance of drugs, alcoholism, having adequate sleep, proper delegation, setting realistic deadlines, avoidance of being too hard on oneself, are effective stress management strategies, as captured in items 2, 5, 6, 7, 10, 11, 12, 12 and 13 which they rated between 2.50 to 4.00. The overall mean of 2.80 shows that University Administrators in, Universities in North Western Nigeria agree on stress management strategies listed in table 4.

\section{Summary of Major Finding}

- The prevalence of stress among University Administrators in Universities in North Western Nigeria is high.

- University Administrators in Universities in North Western Nigeria agree on the various sources of stress that affect them, implying that most of them are under stress.

- University Administrators in Universities in North Western Nigeria agree on the various sources symptoms of stress which they experience in various dimensions.

- University Administrators in Universities in North Western Nigeria does not agree on the various types of management strategies to be used present stress. 


\section{Discussion of Findings}

This study found that the prevalence of stress among University Administrators in Universities in North Western Nigeria was high. That means that none of them was immune to stress as it affects virtually every one of them. This agrees with Edberg (2017). It is very common to hear University Administrators openly confessing that they are under stress and over stretched with little or no respite. This study found that executive stress can be caused by various factors. This is in line with Garnett (2007) and Keith (2017). Heavy work load tend to drain the physical and mental energies of University Administrators leaving them weak and tired. In some cases, University Administrators are forced to work extra hours and to over stretch their physical and mental capacities in order to meet up with urgent deadlines which are sometimes endless. In most cases the University Administrators have to the engaged in multi-tasking with the hope of accomplish many tasks simultaneously, but sometimes they end being unable to focus and achieve one thing at a time. Multitasking is like pursuing two rats [Pat the same time or chewing two hard bones at the same time. Due to excess work, most of the University Administrators have no time for breaks and relaxation as they tend to work round the clock, thereby being tagged workaholics. But even a machine that works continually without rest have the risk of being overheated and even breaking down eventually. Due to exaggerated work hours, the University Administrators does not have time to spare for exercise. With time, lack of exercise results in putting on weight, high sugar levels due to high blood pressure, cardiac problems and other health conditions that can have serious consequences not only in intensifying stress but reducing productivity. Some University Administrators tend to carry files and excess load of office work home to be done at night. This leaves them little or no time to sleep adequately. But sleep deprivation generates stress during the day. In some cases, some University Administrators do not feed properly as they skip meals, or and instead go on energy drinks, sodas, and caffeinated teas as substitutes. In other cases, they tend to over eat as compensation for stress more so as they can afford any kind of food. Wrong diet however tends to affect them in various dimensions. Apart from this the University Administrators is always confronted with excessive pressure as they have to attend to their superiors and at the same time also attend to the problems of their subordinates and the general public. The situation of stress is worsened where the University Administrators dos not delegate duties adequately but tend to handle too many things which ought to have been delegated to reduce his stress. In some cases, the University Administrators may have some pressing family problems and attending to which may conflict with his official duties and this role conflict leaves him anxious and stressful.

The findings of this study showed that the University Administrators in Universities in North Western Nigeria agreed with all the causes of stress discussed so far. The finding is line with Nuget (2017), Keith (2017) and McDowell (2017) who in their various submissions identified some the causes of stress presented. The findings show that although University Administrators have a very high appreciation and knowledge of the causes of executive stress, yet many of themlack genuine commitment to do anything by way of taking concrete action to protect them. Thus, they end up being affected by stress in various dimensions as most of them indicated that they are under stress.

The finding of this study show: that University Administrators in Universities in North Western Nigerian recognized and accepted the symptoms of executive stress to include inefficiency in job performance, declining productivity, irritability, memory lapses, physical and mental fatigue, bodily pains, loss of objectivity, abandoned tasks andfeeling over whelmed. This finding agrees with Julie (2017) and Penelope (2017)who identified various symptoms of executive stress in their various submissions. University Administrators in Universities in North Western Nigeria not only agreed with identified symptoms of executive stress but acknowledged that they experience some of the symptoms of stress on daily basis.

Findings of this study show that University Administrators in Universities in north western Nigeria disagree on the stress management strategies to be used for stress prevention. This find confirms Goldberg (2017), Madison (2017) and Edberg (2017) who noted that University Administrators were unable to determine their stressors as well as their body response signals to stress. Thus, some of them do not exercise regularly and do not have proper diet. Some of them are on self-mediation to boost their energy, some smoke to reduce stress and others deprive themselves of sleep. Thus, in spite of their apparent knowledge of various causes of stress.

\section{Conclusions}

Many University Administrators in Universities in north western Nigeria suffer various degrees of stress The University Administrators are aware of the various symptoms of stress which many of them experience on daily basis. However, they do not agree on stress management strategies to be used to prevent stress.

\section{Recommendations}

Based on the findings of this stress, the following recommendations were made:

- There should be regular workshops, symposiums talk and other programmes to really expand the knowledge of University Administrators on the various causes and source of stress.

- University Administrators must recognize their body's response to stress and take prompt measures to respond positively in order to avoid complications.

- There should be multidisciplinary approaches to stress management especially by medical experts, psychologists, sociologists, guidance counselors and management experts on the consequences of executive stress and best stress management strategies to prevent stress and ensure healthy and effective job performance.

\section{Implication for School Administrators}

Since stress is unavoidable in life, school administrators are expected to lead in organizing public enlightenment programme in other to create awareness among themselves on the danger of stress not only on their professional job 
performance but also on their lives as individuals. They should mobilize experts in their institutions to contribute ideas for effective stress management among University Administrators.

\section{References}

i. Edberg, H. (2017). How to deal with stress: 33 Tips that work. Online: ttps/ / www .posstivityblog.com

ii. Garnett, Y. (2007). The management of executive stress: Eliciting peak performance in the corporate executive. Published by Center for stress education, Abuja and Kaduna: Joyie Graphic Publishers, Kaduna.

iii. Hornby, A.S. (2003). Oxford advanced leaner's dictionary. International Students edition. Network. Oxford University press.

iv. Julie, L. (2017). What is executive stress syndrome? Online: https:/ www.antietyblaster.com. Retrieved 30/ 10/17.

v. Keith, P. (2017). The Myth of executive stress: How tough is it really to be a boss? Online: https :/ / www.scientificarnerica.com

vi. Madison, J. (2017). Learning how to manage stress in the workplace. Online: https://www.cornerst onedernand.com

vii. McDowell, L.S. (2017). Six ways to beat executive job stress. Online: https:/ / www.thrbes.corn. Retrieved 3 0th October, 2017.

viii. Nuget, P.M.S. (2017).What is executive stress? Online https://www.psychologydictionary.org. Retrieved $30 / 10 / 17$.

ix. Penelope, K. (2017). Executive stress complete collection series 1-3. Online: https//www.amazon.co. U.K. Retrieved 30/ 10/ 2017. 